\title{
AVALIAÇÃO FINANCEIRA DE UM PROJETO DE CASA INTELIGENTE PARA UMA RESIDÊNCIA NO CEARÁ
}

\author{
FINANCIAL EVALUATION OF A SMART HOME PROJECT FOR A RESIDENCE IN \\ CEARÁ
}

Recebido em: 08 maio 2020

Aprovado em: 04 jul. 2020

Versão do autor aceita publicada online: 04 jul. 2020

Publicado online: 25 jun. 2021

\section{Como citar esse artigo - American Psychological Association (APA):}

de Souza Dutra, M. D. (2022, jan./mar.). Avaliação financeira de um projeto de casa inteligente para uma residência no Ceará. Exacta. 20(1), 176-197. https://doi.org/10.5585/exactaep.2021.17173.

Submeta seu artigo para este periódico $\beta$

Dados Crossmark 


\title{
AVALIAÇÃO FINANCEIRA DE UM PROJETO DE CASA INTELIGENTE PARA UMA RESIDÊNCIA NO CEARÁ
}

\author{
FINANCIAL EVALUATION OF A SMART HOME PROJECT FOR A RESIDENCE IN CEARÁ
}

${ }^{1} \mathrm{PhD}$

Polytechnique Montréal

Montreal, QC - Canada.

michaeldavid.dutra@polymtl.ca

Recebido em: 08 maio 2020

Aprovado em: 04 jul. 2020
Resumo: Casas inteligentes são uma tendência mundial. Elas permitem o uso otimizado de energia, permitindo que as famílias reduzam as contas de eletricidade ou até lucrem. O número de residências inteligentes nos EUA e no Reino Unido atingiu 40,3 milhões e 5,3 milhões, respectivamente, em 2018. Até 2024, 53,1\% de todos os lares nos EUA e $39 \%$ no Reino Unido são esperados a se tornarem residências inteligentes. No entanto, no Brasil, existem apenas 1,2 milhão de residências inteligentes registradas em 2018. Embora as residências inteligentes pareçam ser o futuro das residências, muitos clientes têm a percepção de que a transição das residências atuais para as residências inteligentes não é lucrativa devido ao investimento inicial necessário e o risco de não haver retorno para cobrir esse investimento. A literatura atual não responde a necessidade de um proprietário residencial cearense em encontrar o melhor conjunto de máquinas e aparelhos elétricos, da perspectiva financeira, para a adoção de uma casa inteligente, objetivo deste trabalho. Este artigo propõe um estudo de caso com o objetivo de avaliar a rentabilidade de muitos projetos de implementação de casas inteligentes para uma determinada casa no Ceará. Utilizando metodologia pautada na Pesquisa Operacional, e programação matemática com otimização exata para a maximização do valor presente líquido, os resultados indicam o conjunto de eletrodomésticos / tecnologias que devem ser adquiridos para que o investimento feito pelo agregado familiar tenha um retorno financeiro positivo.

Palavras-chave: Otimização. Casa inteligente. Energia. Valor presente líquido.

Abstract: Smart homes are a trend worldwide. They allow optimized energy usage, allowing households to reduce electricity bills or even make profits. The number of smart homes in US and UK attained 40.3 million and 5.3 million, respectively, in 2018. By 2024, 53.1\% of all households in US and 39\% in UK will be expected to become smart homes. However, in Brazil, there are only 1.2 million smart homes registered in 2018. Although smart homes seem to be the future for homes, many customers have the perception that a transition from current homes to smart ones is unprofitable due to the amount of initial investment required and the risk of no returns to cover this investment. This paper proposes a case study with the goal to evaluate the profitability of many projects of smart homes implementation to a given house in Ceará. Focusing on the net present value maximization, the results indicate the set of home appliances/technologies that should be acquired so that the investment made by the householder has a positive financial return.

Keywords: Optimization. Smart home. Energy. Net present value. 


\section{Introdução}

Em 2006, European Technology Platform Smart Grid definiu uma rede inteligente como uma rede elétrica que integra usuários, consumidores e geradores, a fim de produzir e fornecer eletricidade em meios econômicos, seguros e sustentáveis. De acordo com o Statista Digital Market Outlook, o número de residências inteligentes nos Estados Unidos já ultrapassa 40 milhões e é projetado para 68,5 milhões em 2024. Na China existem 19,5 milhões de residências inteligentes e 62,4 milhões são esperadas até 2020. Na Grã-Bretanha 10 milhões de residências serão inteligentes até 2022, tendo atualmente cerca de 5,3 milhões já existentes. Seguindo de forma mais suave essa tendência de crescimento, o Brasil registrou 1,2 milhão de residências inteligentes (1,9\% do total de residências) em 2018. Analisando os dados do Statista Digital, conclui-se que o número de casas inteligentes tem aumentado rapidamente somente em algumas regiões no mundo.

De acordo com Sanguinetti et al. (2018), uma importante barreira para residências inteligentes é a percepção do consumidor de que a adoção de tecnologia para residências inteligentes não vale o investimento. Considerando que o investimento para transformar casas comuns em casas inteligentes é representativo, os proprietários precisam conhecer a rentabilidade do investimento nessa transição para diminuir os riscos, e, portanto, o medo de investimento. Além disso, presume-se que os moradores estejam interessados em gerenciar suas contas de energia elétrica, garantindo um certo nível de conforto. Portanto, uma transição para casas inteligentes deve ser lucrativa.

Uma maneira de investir na transição de casas inteligentes é através da aquisição de componentes de casas inteligentes (SHCs), que são definidas como tecnologias, máquinas e equipamentos disponíveis para casas inteligentes, como turbinas eólicas (WTs), painéis fotovoltaicos (PVs), sistemas de armazenamento de energia (ESSs), veículos elétricos (EVs), aquecimento, ventilação e ar-condicionado (HVAC), aquecedores de água (WHs), coletores solares (SCs), chuveiro elétrico, geladeira, freezer e eletrodomésticos. A condição básica é que estes aparelhos sejam conectados e controlados por um computador, o qual se nomeia sistema de gestão de energia residencial. O desafio recorrente neste contexto é definir quais destes SHC adquirir de forma a ter um projeto com o melhor nível de investimento.

Limitando a discussão no território brasileiro, Dranka et al. (2020) sugeriu a necessidade de estudos focados em medir a propensão do consumidor residencial a adotar medidores inteligentes no Brasil. Visto que medidores inteligentes são a porta de entrada para a transição em direção a adoção de casas inteligentes, estudos sobre a propensão do consumidor residencial a adotar medidores inteligentes no Brasil se relacionam com a propensão do consumidor residencial a investir em residências inteligentes no Brasil. Dutra et al. (2019) mostram que o retorno de um investimento difere dependendo da localização do projeto e do projeto em si. Além disso, a avaliação da atratividade 
econômica de um projeto exige modelos matemáticos em dois níveis, um para representar a operação de rotina doméstica inteligente e o segundo para escolher um projeto dentro de um portifólio de projetos que tenha o melhor retorno sobre o investimento. Salienta-se que cada projeto tem uma duração de vários anos. No entanto, raros são os trabalhos que analisam a lucratividade de investimentos nestas condições em regiões específicas do Brasil, sendo a motivação deste trabalho ajudar a preencher essa lacuna.

Esse trabalho propõe um estudo de caso sobre o retorno de se investir em uma casa inteligente na região de Fortaleza, Ceará. Embora o nordeste brasileiro tenha níveis de radiação solar elevados, inexiste estudos para guiar um investidor cearense na adoção de uma casa inteligente. De forma objetiva, este trabalho responde a seguinte pergunta: "Financeiramente, é viável a adoção de uma casa inteligente para qualquer residência no Ceará ?". Para tanto, adotamos um estudo quantitativo, usando ferramentas da Pesquisa Operacional.

\section{Trabalhos relacionados}

Esta seção fornece uma revisão bibliográfica de trabalhos recentes sobre o análise econômica de projetos envolvendo a aquisição de componentes de casas inteligentes, foco deste estudo.

No contexto dos países europeus, Gur et al. (2018) afirmam que nem baterias novas nem reutilizadas tornam os sistemas de baterias mais placas fotovoltaicas lucrativos, mas cada país tem seus motivos específicos.

Considerando a Suíça, Schopfer et al. (2018) apresentam que os sistemas de baterias fotovoltaicas não são lucrativos devido ao alto custo das baterias, mas os sistemas compostos somente com painéis solares podem ser lucrativos. Considerando 4190 perfis de carga das famílias, os resultados mostram que há alta variabilidade na configuração ideal do sistema e na lucratividade devido às especificidades individuais da família, mesmo para consumidores com demanda anual total semelhante.

O trabalho de Van Der Stelt et al. (2018) propõe uma análise tecnológica e econômica de um armazenamento compartilhado de energia e baterias domésticas para consumidores residenciais com aparelhos inteligentes. Utilizando dados de geração fotovoltaica e demanda real de 39 famílias na Holanda, os autores computaram o payback para os sistemas mencionados. Um problema de otimização linear inteiro misto (MILP) minimiza o custo de aquisição de energia da rede. Os usuários podem injetar eletricidade na rede, mas não há recompensa por isso. O plano do horizonte para o problema de agendamento é de um ano. Os resultados mostram inviabilidade econômica para os sistemas, que têm um retorno que varia de 26 a 43 anos.

Yu (2018) apresenta um caso francês: considerando o declínio de custo de baterias de lítio-íon e painéis fotovoltaicos, o autor estuda a lucratividade dos sistemas compostos por esses dois SHCs e 
sua integração maciça em sistemas de energia. Os preços de painéis fotovoltaicos no futuro foram estimados pelo método da curva de experiência. Uma medida de razão, baseada no valor presente líquido, é usada para determinar a viabilidade econômica dos sistemas. O aquecimento elétrico é ignorado no estudo. Do ponto de vista do usuário final, os resultados mostram que as baterias de lítioín com sistema fotovoltaico têm uma alta probabilidade de serem rentáveis até 2030. Da perspectiva da rede, um sistema de fotovoltaicos sem bateria tem um impacto maior do que um sistema composto PVs com baterias, uma vez que este último precisa de menos injeção na rede.

Chatzisideris et al. (2019) investigam os ganhos ambientais e econômicos de placas fotovoltaicas orgânicas (OPV) para o autoconsumo combinado com as baterias no contexto do setor residencial grego e dinamarquês. Nos dois países, o consumo médio das famílias de 4000 kWh por ano é considerado como entrada para um framework de seis etapas no qual existe um método de simulação. Considerando um projeto de vida útil de 20 anos e 100 combinações de tamanhos de sistema (OPV e bateria com um tamanho discreto entre, respectivamente, 1-10 kWp e 1-10 kWh), os resultados mostram que sistema com somente de OPV de 1 kWp oferece a melhor opção para os dois países, com um VPL de 1216 euros para a Dinamarca e um VPL de 1164 euros para a Grécia. Considerando uma redução de preço do OPV, os sistemas com baterias e OPV são mais lucrativos que os sistemas com somente OPV quando o custo do OPV é no máximo 0,9 euro/Wp e 1,6 euro/Wp, respectivamente, para a Dinamarca e a Grécia.

Bai et al. (2019) apresentam uma análise econômica de baterias de veículos elétricos de segunda vida combinadas com painéis fotovoltaicos para muitas províncias da China, considerando os setores residencial, comercial e industrial. O VPL é calculado considerando um projeto de vida útil de 30 anos. Duas estratégias para o uso de baterias são consideradas: a primeira para aumentar a taxa de autoconsumo da produção fotovoltaica e a segunda para aumentar a TA e também o nivelamento da carga. Os proprietários de algumas regiões chinesas só conseguem lucrar com a segunda estratégia. Focalizando apenas o painel fotovoltaico, sua implementação beneficiará todos os setores de todas as províncias, considerando o subsídio do governo. Sem subsídio, apenas $61 \%$ das regiões possui um VPL positivo para o setor residencial, considerando uma taxa de autoconsumo de $40 \%$.

Usando dados reais para a produção de energia fotovoltaica e o consumo de eletricidade, coletados por um ano em uma residência no Reino Unido, Uddin et al. (2017) estudaram a viabilidade econômica de baterias e energia fotovoltaica. Eles desenvolvem um modelo detalhado e confiável de degradação da bateria. Eles supuseram que, próximo ao 50 ano, a bateria tenha uma perda de eficiência importante; portanto, o uso e a geração anuais de eletricidade são definidos nos mesmos cinco anos. A dimensão do tempo é usada apenas no modelo de degradação da bateria. A avaliação econômica é feita através da economia anual, ou seja, a soma da receita menos as despesas de um ano. Os resultados mostram que, sem considerar o custo da degradação da bateria, o sistema "PV-4 kWp" e o sistema "PV4 kWp + bateria-2 kWh" possuem uma taxa de economia anual de 185 libras e 193 libras, 
respectivamente. No entanto, considerando o custo de degradação, a bateria torna o projeto não rentável.

No contexto da República Tcheca, onde há um programa feed-in-tariff (FIT), Kichou et al. (2019) propõem dois modelos de simulação (um para o verão e outro para o inverno) para encontrar a solução ideal entre desempenho e retorno financeiro, considerando sistemas compostos por painéis fotovoltaicos, CHPs e baterias para um edifício de pesquisa. O desempenho é diretamente proporcional a uma proporção de energia comprada da rede em relação ao autoconsumo. O custo financeiro é medido pelo VPL e pelo payback. Os autores usaram uma abordagem de economia anual. Os resultados mostram que o sistema existente no edifício tem um payback de 28,7 anos, que é maior que o tempo de vida do projeto: 25 anos. No entanto, aumentando a capacidade do PV em $24.2 \mathrm{kWp}$ e usando as estratégias de controle fornecidas como saída pela simulação, o retorno do investimento diminui para 9,7 anos com um VPL de 35.49 euros. Vale ressaltar que as estratégias de controle são o principal motor das melhorias econômicas.

Akter et al. (2017) propõem uma estrutura que fornece medidas econômicas para avaliar um sistema de bateria com painéis fotovoltaicos considerando um caso de estudo australiano. Os resultados mostram que o VPL e o payback de um sistema com apenas painéis fotovoltaicos são melhores do que sistemas com painéis fotovoltaicos e baterias. Os painéis fotovoltaicos são economicamente aceitáveis em sistemas na rede, mas não são lucrativos em sistemas fora da rede após um limite de capacidade instalada devido ao excesso de energia. Como metodologia, as avaliações econômicas são realizadas considerando-se um projeto com vida útil de 25 anos para diferentes cenários, usando sua simulação própria.

Mais tarde, Say et al. (2018) estudaram a lucratividade de 441 combinações de bateria e sistema fotovoltaico em Perth, Austrália. A faixa de pico de potência do painel fotovoltaico e capacidade da bateria variou, respectivamente, de 0 a $10 \mathrm{kWp}$ com um tamanho de passo de 0,5 kWp e de 0 a $20 \mathrm{kWh}$ com um tamanho de passo de $1 \mathrm{kWh}$. O tempo de vida do projeto foi definido para 10 anos. Os anos de 2018 e 2013 foram utilizados como candidatos para a data de instalação do projeto. Nos dois anos, várias combinações de sistemas usando somente de bateria ou somente PV tiveram um VPL positivo. Então, considerando diferentes taxas de aumento dos preços da eletricidade (TAPE), o VPL é calculado considerando que os projetos começam em cada ano de 2018 a 2033. Novamente, existem várias combinações rentáveis de sistemas compostos por somente PV ou por somente bateria, mas os resultados mostram que as baterias devem ser evitadas antes de 2020 e 2024 para um TAPE anual de $5 \%$ e $0 \%$, respectivamente. Uma análise semelhante é realizada para diferentes feed-in-tariff (FITs). Esses resultados respondem à pergunta: "Quando o PV e/ou o baterias devem ser instalados para maximizar a lucratividade?". De forma similar, essa pergunta é respondida em Dutra et al. (2019). 
Alguns trabalhos recentes também estudaram os benefícios econômicos de outros componentes de casas inteligentes (SHCS). Um projeto de casa é estudado por Xie et al. (2017). A análise de payback para micro-CHP, materiais de mudança de fase, bombas de calor, coletor solar e painéis fotovoltaicos são descritos. O artigo mostra um payback de 13 e 6,5 anos ou mais para micro-CHP e aquecedores de água, respectivamente. A metodologia utilizada foi uma simulação com o software de design, SketchUp-Trimble.

A integração de veículo elétrico com painel fotovoltaico no contexto do Havaí é apresentada por Coffman el al. (2017). O custo total de propriedade é calculado para seis veículos elétricos, cinco veículos elétricos híbridos (HEV) e seis veículos com motores de combustão interna (ICEV). Os resultados mostram que os veículos elétricos são menos atraentes que o ICEV ou que o HEV se os subsídios não forem levados em consideração. Se forem considerados subsídios, apenas um Nissan Leaf se torna mais atraente do que outros HEV e ICEV. Se os painéis fotovoltaicos são considerados além do veículo elétrico, os veículos elétricos se tornam mais favoráveis economicamente.

Anvari et al. (2020) projetaram e analisaram um sistema de cogeração para um edifício de referência em Pisa, Itália. Duas estratégias foram comparadas via VPL, considerando dois contextos: os preços do gás e da eletricidade da Itália e do Irã. Na primeira estratégia, um sistema de cogeração é proposto de acordo com o consumo máximo de energia de aquecimento do edifício. Na segunda estratégia, um sistema de cogeração de tamanho menor é dimensionado para geração simultânea de carga de resfriamento e aquecimento do edifício de referência. Os resultados mostram que a primeira estratégia tem um período de retorno de 9,4 anos para a Itália e 16 anos para o Irã. A segunda estratégia não é lucrativa para o Irã e tem um payback de 24 anos para a Itália.

Mazzeo (2019) investiga 100 sistemas compostos por painéis fotovoltaicos, baterias e o Nissan Leaf como veículo elétrico em um contexto residencial. A capacidade de painéis fotovoltaicos e baterias é determinada para maximizar o VPL de duas maneiras independentes: uma que restringe a quantidade de energia comprada da rede (via I), outra restringe a quantidade de energia enviada à rede (via II). São utilizados perfis de carga doméstica diários, mas os valores médios são considerados durante a vida útil da bateria e dos sistemas fotovoltaicos. A recarga do veículo é permitida apenas em horas noturnas, entre 10 PM - 8 AM. Comparando com os ICEVs, os resultados mostram que o sistema residencial PVESS-EV possui um VPL positivo após um limite da distância percorrida pelo EV. O VPL varia de quase 0 a 72.360 euros. Dependendo das distâncias diárias de veículo elétrico percorridas, são fornecidos dois conjuntos de soluções para otimizar a capacidade da bateria e a potência de pico PV: para o modo I, bateria e painel fotovoltaico, a potência de pico varia de 12 a 27 kWh e de 6 a $10 \mathrm{kWp}$, respectivamente; para o modo II, a capacidade da bateria é $3 \mathrm{kWh}$ e o pico de potência do PV varia de 2 a 3 kWp.

Com foco no autoconsumo fotovoltaico, um modelo MILP de otimização para a configuração e dimensionamento de energia fotovoltaica, baterias e bombas de calor é apresentado por Beck et al. 
(2017). O aquecimento da água e do espaço é modelado sem restrições técnicas, apenas o fluxo de energia é considerado. As bombas de calor e baterias têm mais detalhes em seus modelos. Três perfis de carga coletados durante os anos de 2012 e 2013 de residências alemãs e perfis de carga solar da cidade de Stuttgart são levados em consideração pelo modelo. Combinando dois FITs e três cenários de preço da eletricidade, os resultados mostram que a potência nominal ideal da bomba de calor, painel fotovoltaico e aquecedor elétrico é raramente influenciada pelo aumento do preço da eletricidade ou pelos FITs. Em todos os seis cenários, a capacidade nominal das baterias é menor que $5 \mathrm{kWh}$ e a potência de pico do painel fotovoltaico varia de 0 a $10 \mathrm{kWp}$. A análise de sensibilidade fornece uma análise mais profunda dos preços e consumo do usuário. Os autores concluem que o dimensionamento de PV e de baterias depende principalmente da demanda do usuário.

A literatura tem focado em conjuntos específicos ou isolados de SHC quando o tópico é análise econômica. Além disso, a maioria dos artigos analisou a rentabilidade de painéis fotovoltaicos e baterias. Observe que esses resultados destacam a importância de considerar a análise econômica para cada sistema específico, mesmo que os sistemas tenham locais idênticos, o que é explicitamente mencionado em Schopfer (2018), Dutra (2019), Beck (2017): a eficiência econômica dos SHCs depende de preços, leis regulatórias e comportamento do usuário.

Existem muitos outros estudos com foco na análise econômica de sistemas somente fotovoltaicos e baterias fotovoltaicas em diferentes locais residenciais. Consulte O'Shaughnessy et al. (2018) para uma revisão que resume muitas aplicações em vários países. No entanto, poucos estudos trataram a lucratividade de casas inteligentes na América do Sul. Focando os sistemas fotovoltaicos, as análises econômicas são apresentadas por Coria et al. (2019) e por Espinoza et al. (2019) nos casos argentino e peruano, respectivamente. A contribuição deste trabalho é um estudo para guiar um investidor cearense na adoção de uma casa inteligente. De forma objetiva, este trabalho responde a seguinte pergunta: "Financeiramente, é viável a adoção de uma casa inteligente para qualquer residência no Ceará ?".

\section{Metodologia}

\subsection{Procedimento metodológico}

Este estudo utiliza modelos matemáticos para representar a realidade. Cada elemento de consumo de energia, ou seja, cada máquina ou appliance de uma residência cearense é representado por equações ou inequações que representam restrições do funcionamento do aparelho. O consumo de energia em uma residência gera custo. Tal custo é modelado através de uma equação matemática, denominada função objetivo, a qual objetiva-se minimizar seu valor. O procedimento metodológico é exibido no Quadro 1. 
Primeiramente, é necessário identificar o problema real. Muitas vezes, modelos matemáticos complexos para representar o problema real são intratáveis computacionalmente, portanto, usa-se hipóteses simplificadoras. Um modelo matemático deve ser resolvido com algum método de solução. A solução do modelo matemático é utilizada para validar o modelo matemático. Em caso de inconsistências, deve-se melhorar o modelo matemático, até que a solução do modelo matemático seja aceitável.

\section{Quadro 1}

Procedimento metodológico

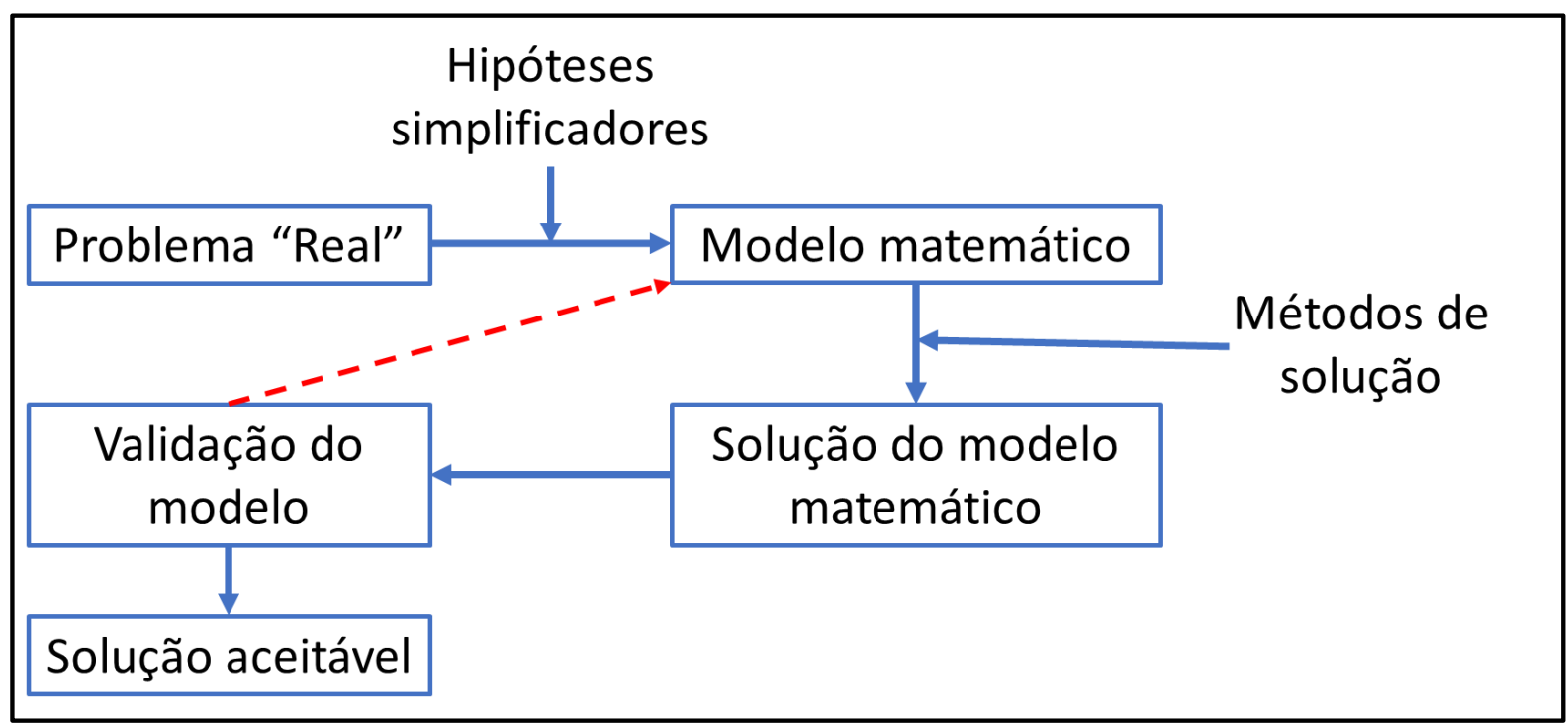

Fonte: Autoria própria.

O modelo matemático pode ser formulado da seguinte forma:

$$
\operatorname{Min} f(x)=a x+b: x \in \Omega
$$

onde é $\mathrm{f}(\mathrm{x})$ a função objetivo a ser minimizada, a e b são vetores que representam os parâmetros constantes do modelo e x é o vetor de varáveis do modelo que pertencem a uma região de viabilidade $\Omega$, a qual é formada pelas restrições.

Em nosso estudo, objetiva-se escolher qual o melhor conjunto de SHCs para ser adquiridos pelo proprietário da residência de forma a maximizar o retorno sobre o investimento.

Os modelos para dispositivos de usuários são baseados em Dutra et al. (2018), os qual formulou modelos matemáticos representativos e confiáveis para SHCs. O modelo que integra todos esses dispositivos e que otimiza o fluxo de energia na residência em Dutra et al. (2018) precisa de 10 páginas. Portanto, para resumi-lo, apresentamos o Quadro 2. 
Quadro 2

Esquema do modelo matemático

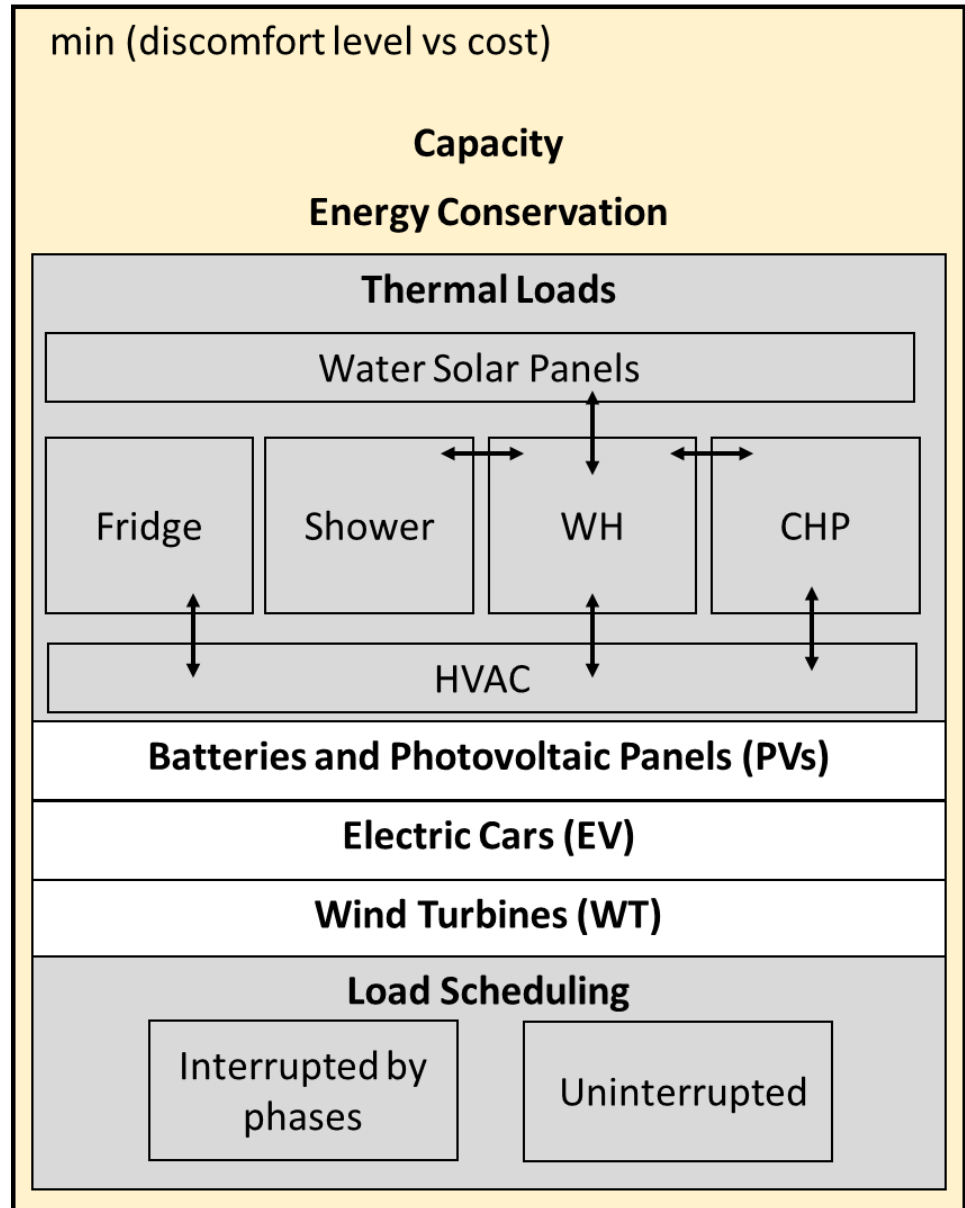

Fonte: Autoria própria.

No Quadro 2, vários SHCs são considerados e as flechas entre eles representam relacionamentos, que são modelados como restrições em Dutra et al. (2018). Massa térmica do edifício, radiação solar, velocidade do vento etc. são caracterizados neste trabalho. Observe que um chefe de família pode ter qualquer combinação de SHCs. Portanto, há um número de possibilidades de escolha igual a $2^{\mathrm{n}}-1$, onde $\mathrm{n}$ é o número de SHCs da Tabela 1.

Nossa estratégia é comparar o resultado de $2^{n}-1$ problemas de otimização que devem ser resolvidos. Cada problema de otimização corresponde a um possível projeto de investimento. No nosso caso, temos $n=9$, e, portanto, 511 possibilidades, ou seja, 511 projetos possíveis. Queremos encontrar o projeto que tenha a melhor estimativa de ganho com o investimento.

Considerando que os projetos têm duração de 25 anos, para cada dia destes 25 anos, o modelo matemático para cada projeto é otimizado, e, portanto, uma solução de custo é encontrada. Estas soluções são comparadas ao gasto atual do morador, obtendo assim economias para a implementação 
de cada projeto. Adicionando, a estas economias, custos ao longo do tempo, podemos calcular o payback, o retorno sobre o investimento e o valor presente líquido.

Vamos considerar $D^{p}$ como a duração do projeto em anos, $P a y^{B}$ como o payback, ou seja, período de retorno do projeto em anos, $S$ como a economia do projeto em $\mathrm{R} \$$ proporcionada em relação a não se fazer nada, $T$ como o investimento total em $\mathrm{R}$ e $R$ como o retorno do investimento em $\mathrm{R} \$$. Assim, o payback é calculado de acordo com Akter et al. (2017 - Seção 3.4) como $P a y^{B}=D^{p} \times T \times I \times S$ e o retorno do investimento como $R=S-T$. Considerando também $C_{t}$ como entrada líquida de caixa durante o período t, $C_{0}$ como o custo total inicial de investimento e $r$ como taxa de retorno exigida, o VPL é dado pela Equação abaixo:

$$
V P L=\sum_{t=1}^{D^{p}} \frac{C_{t}}{(1+r)^{t}}-C_{o}
$$

VPL é o valor de todos os fluxos de caixa futuros (positivos e negativos) durante toda a vida útil de um investimento descontado para o presente. Um investimento com um VPL positivo será rentável e um investimento com um VPL negativo resultará em uma perda líquida. Neste documento, o VPL é usado para considerar o valor futuro do dinheiro para uma transição personalizada para casas inteligentes. Um investimento com um VPL negativo resultará em uma perda líquida. Nosso objetivo é escolher uma dessa possibilidades que tenha o maior o valor presente líquido (VPL).

Existem algumas hipóteses usadas nesta fase. Primeiro, como alguns SHCs têm uma vida útil inferior a 25 anos, o custo total aumentou proporcionalmente. Por exemplo, se o PV do componente tem uma vida útil de 12 anos, é necessárias 3 unidades desse componente para atingir 25 anos de projeto. Segundo, salvo indicação em contrário, os custos de manutenção não são considerados: uma vez que a garantia termina, o SHC é substituído por um novo. Vale ressaltar que outra opção é usar fazer manutenção para cada $\mathrm{SCH}$, considerando o projeto específico. Isso poderia, por exemplo, aumentar a vida útil do PV anterior, de maneira a usar 2 unidades em vez de 3, melhorando o VPL. A previsão de custos de manutenção preventiva e preditiva para cada SHC está fora do escopo deste trabalho.

A inflação local não é considerada. No entanto, sem perda de generalidade, a inflação local pode ser considerada juntamente com o parâmetro taxa de retorno requerida. Este trabalho supõe que um cliente deseja adquirir um sistema no ano de 2020. A taxa de retorno requerida é considerada igual a $12 \%$, a qual inclui considerações sobre a inflação nacional. 


\subsection{Dados para os parâmetros}

Esta seção apresenta os dados referentes a localização de uma residência candidata a se tornar inteligente, bem como as várias possiblidades de projetos de investimento. Em seguida, apresenta-se o modelo matemático utilizado e as hipóteses consideradas.

\subsubsection{Dados sobre geografia}

A Figura 1 mostra uma fotografia via satélite da residência sob estudo, a qual se localiza nas coordenadas geográficas $3^{\circ} 44^{\prime} 07.7^{\prime \prime S ~ 38 ³ 0 ' 36.9 " W . ~}$

Figura 1

Localização da residência sob estudo

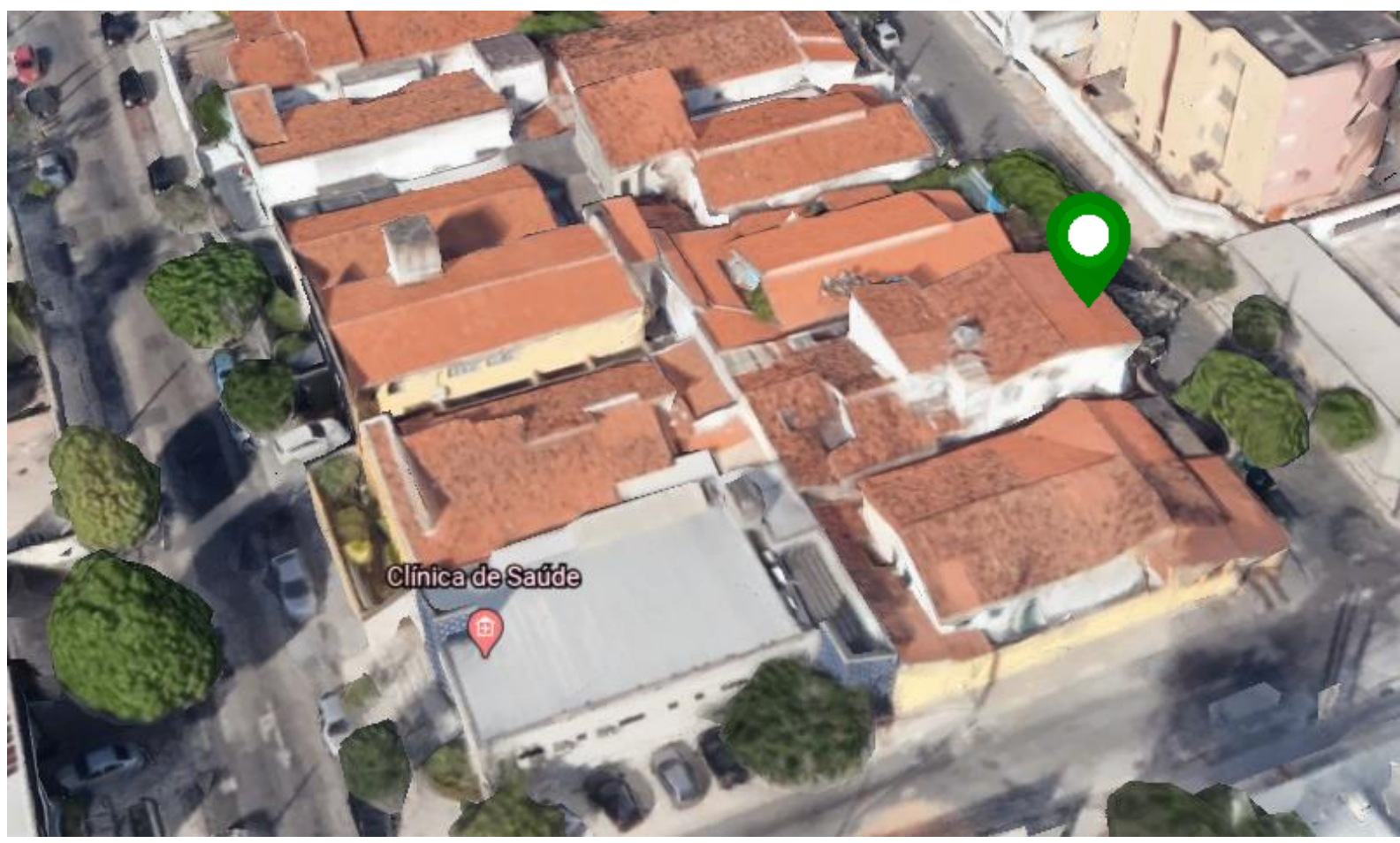

Fonte: Google Earth, 2020.

Temperaturas mensuradas na estação meteorológica mais próxima da residência são apresentadas pelas Figuras 2 e 3. Fortaleza tem claridade solar conforme a Figura 4. 
Figura 2

Temperatura média horária

\section{Temperatura média horária}

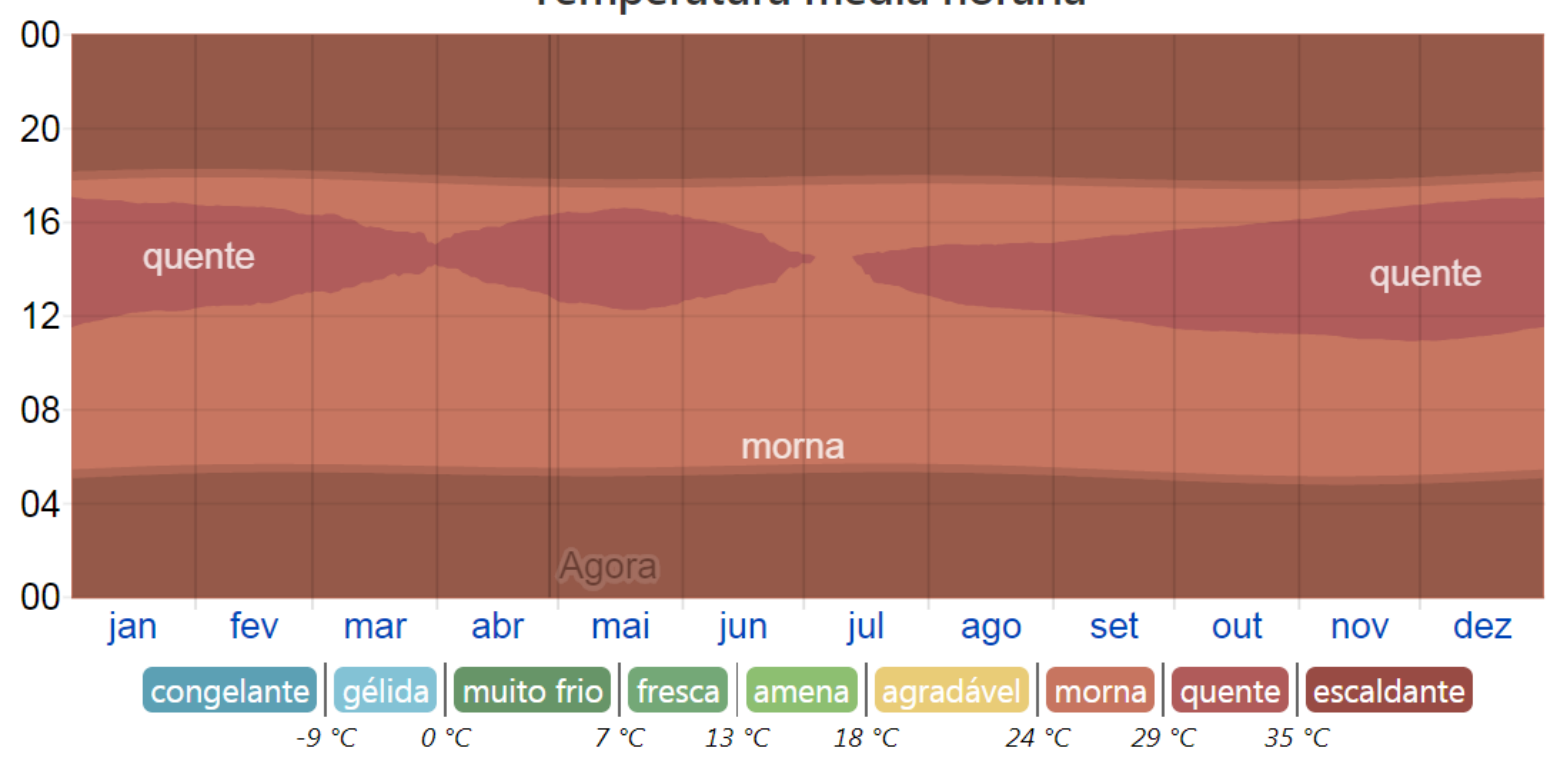

Fonte: https://pt.weatherspark.com/. Acessado em abril de 2020.

Figura 3

Temperaturas máximas e mínimas médias

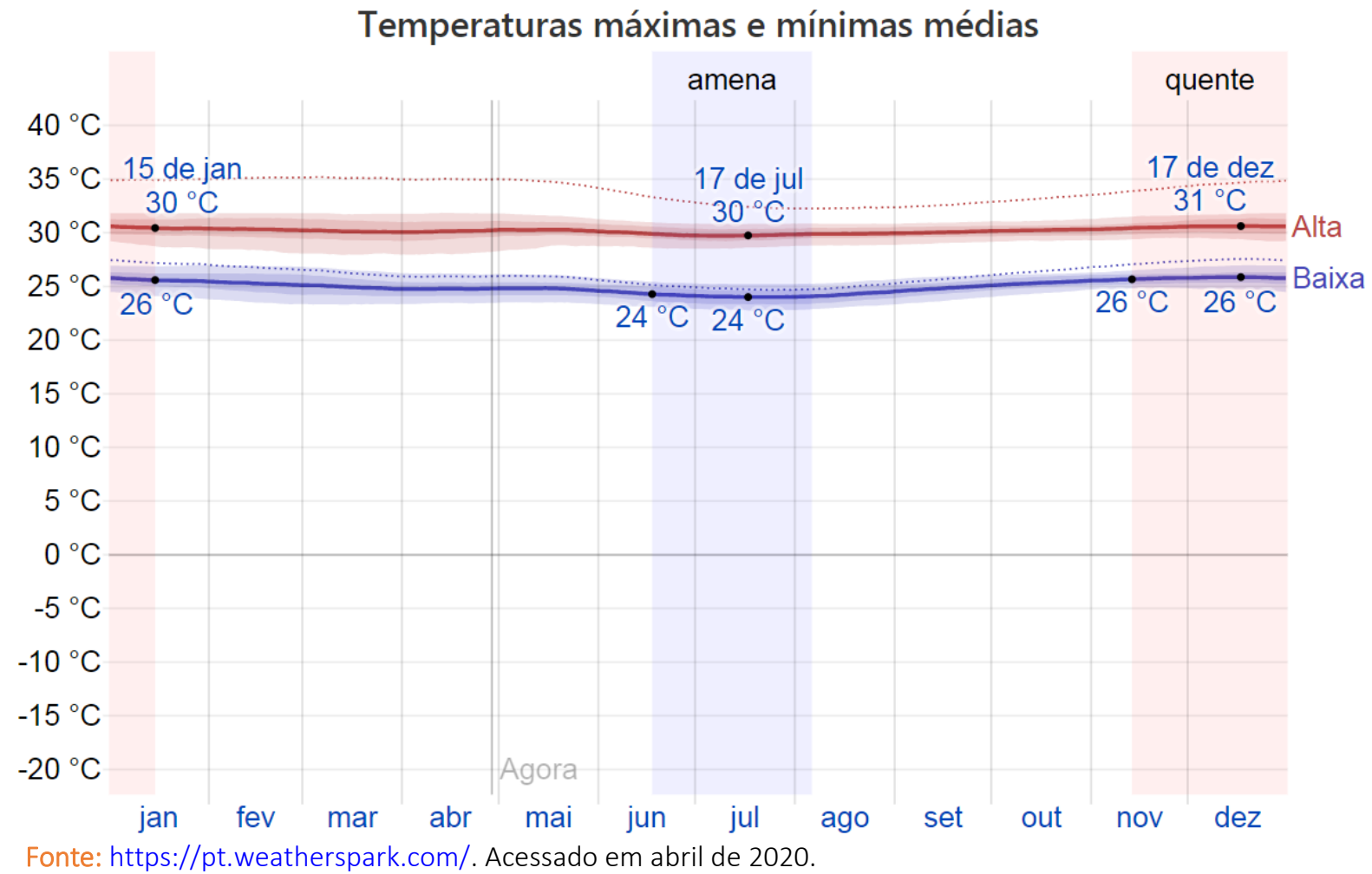


Figura 4

Categorias de nebulosidade

\section{Categorias de nebulosidade}

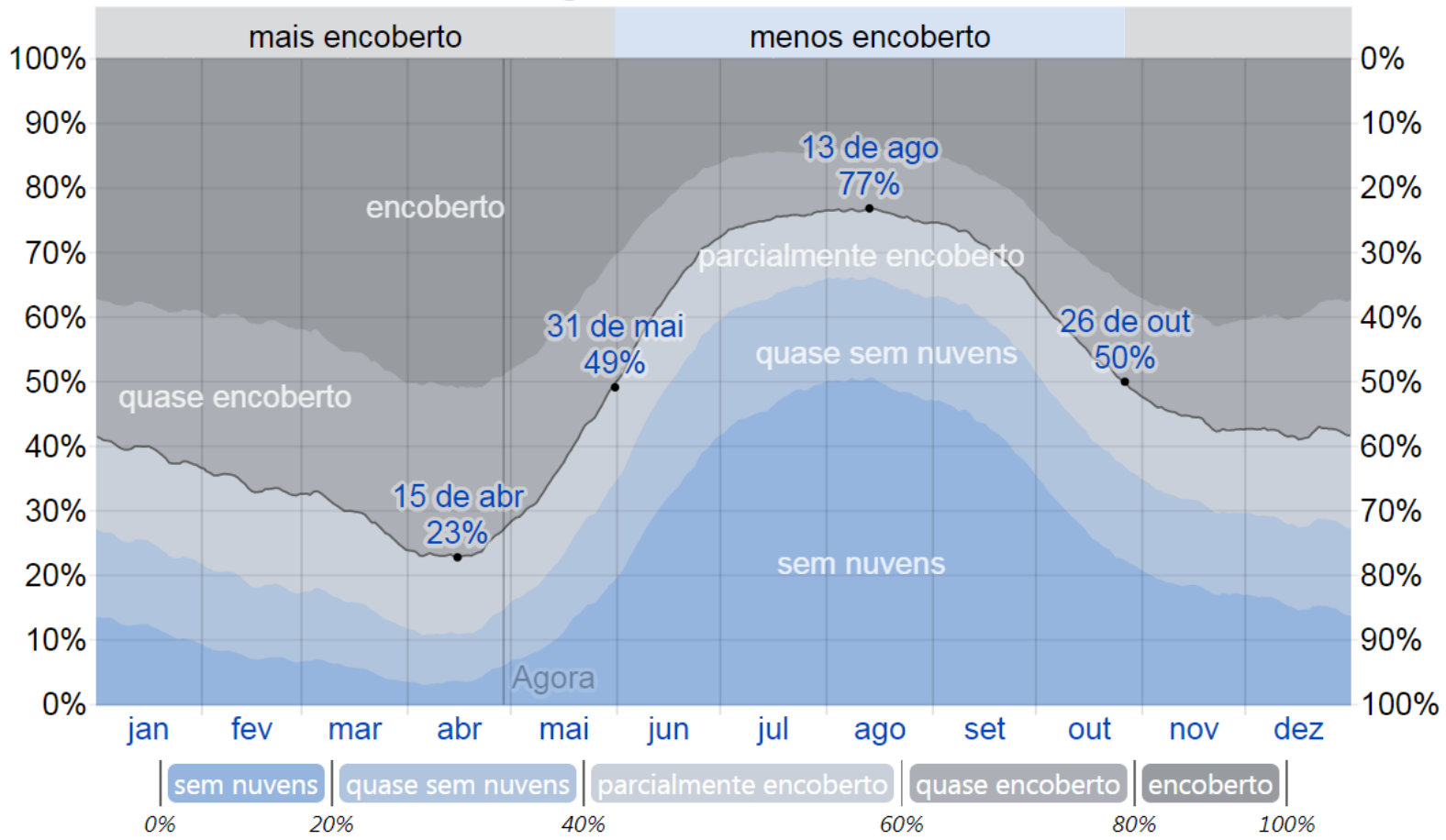

Fonte: https://pt.weatherspark.com/. Acessado em abril de 2020.

Em nosso trabalho, dados climáticos dentro de um dia são necessários. Geralmente, tais dados não são fornecidos com detalhes em minutos em estacoes meteorológicas, sendo necessários medições e projeções com base em modelos probabilísticos. Esse artigo, utiliza dados obtidos de ASHRAE (2013, capítulo 14). Os dados de velocidade do vento foram obtidos em Leite et al. (2006), os quais podem ser aproximados, também, utilizando intervalos de confiança representados na Figura 5. 
Figura 5

Velocidade média do vento

\section{Velocidade média do vento}

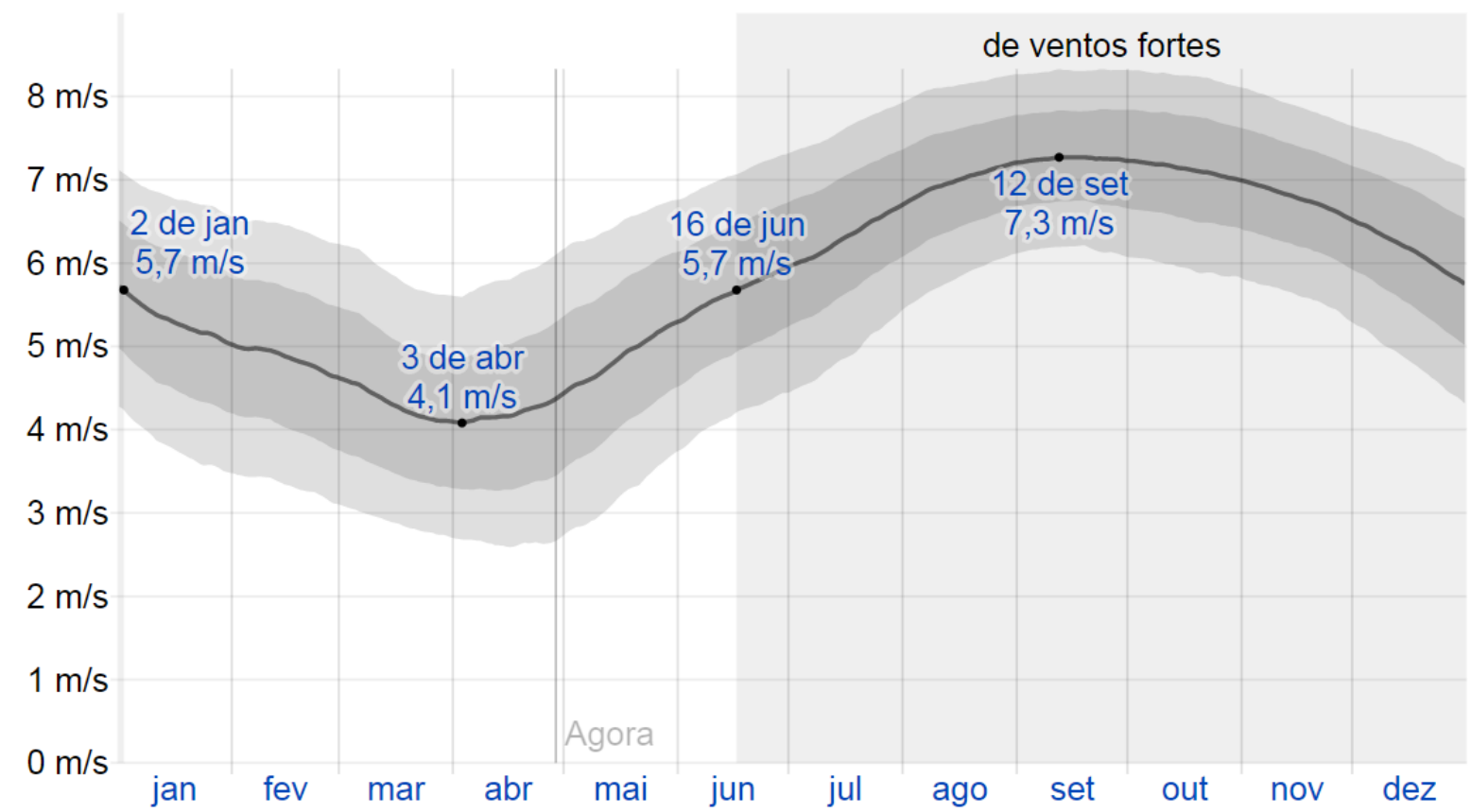

Fonte: https://pt.weatherspark.com/. Acessado em abril de 2020.

\subsubsection{Dados sobre preços}

No Brasil, existem duas opções de preços: a tarifa convencional e a tarifa branca, as quais são representadas na Figura 6.

A tarifa convencional é constante. Já a tarifa branca tem um preço único para fins de semana e feriados, mas três preços distintos dentro de um dia durante dias úteis, correspondendo a três intervalos de horas, o que é chamado na literatura como Time-of-Use. Estes três patamares são definidos da seguinte forma:

1. Horário de pico: três horas diárias consecutivas definidas pelo distribuidor.

2. Horário de pico intermediário: a hora anterior e a hora posterior ao horário de pico.

3. Horas de pico: as horas restantes do dia. 
Figura 6

Tarifas de eletricidade no Brasil

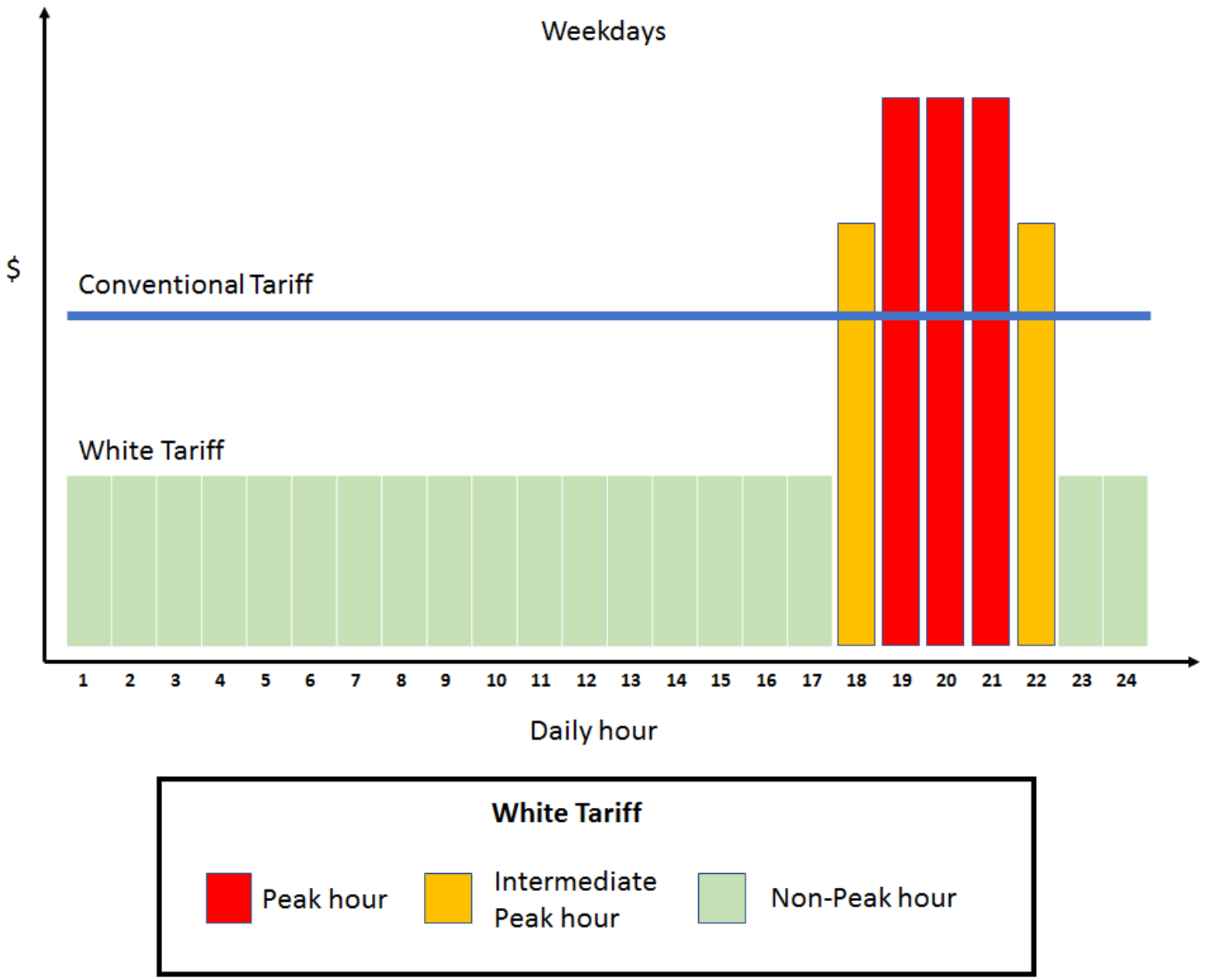

Fonte: ANEEL.

Este estudo considera a tarifa branca os valores de eletricidade publicados em abril de 2020. Para tanto, calculou-se a tarifa total, seguindo Menezes (2015 - p. 57), o que é condizente com a tarifa cobrada pela companhia de energia local (Enel Distribuição Ceará).

Ainda em relação a tarifas, existe a Tarifa Social de Energia Elétrica, definido pela lei federal no 12.212, de 20 de janeiro de 2010. Trata-se de um desconto no bloco de consumo mensal do usuário conforme um dos seguintes critérios:

- Para a parcela de consumo abaixo de 30 kWh / mês, o desconto é de 65\%.

- Para a parcela entre 31 e 100kWh / mês, o desconto é de 40\%.

- Para a parte entre 101 e 220kWh / mês, o desconto é 10\%. 
O Brasil possui um incentivo de compensação de energia injetada na rede (net metering). Se a energia injetada na rede for maior que a consumida, o cliente receberá um crédito de energia para consumo futuro.

As informações sobre o conjunto SHCs estão resumidas na Tabela 1. Nesta tabela, cada elemento de SHCs é anunciado na primeira coluna, enquanto quantidade, marca e modelo são descritos na segunda coluna. A terceira coluna fornece a garantia (dados explicitamente disponíveis nas folhas de dados (data sheet) ou, se não disponíveis, no site dos fornecedores), a qual é considerada como sua vida útil. Os preços são apresentados na quarta coluna. Finalmente, a última coluna adiciona o custo de instalação médio de fornecedores locais à quarta coluna.

\section{Tabela 1}

Informações sobre SHCS

SHC

PV 3.5kWp

Bateria 26kWh

WT 3kW

SC

HW

EV

PV 6.5kWp

Bateria 13kWh

WT 7.5kW

Fonte: Autoria própria.

\section{Quantidade Marca e Modelo}

\section{$14 \times$ CS CS5P-250M}

$2 \times$ Tesla Powerwall

$2 \times$ Kit Gerado de Turbina Eólica 1.5kW

$$
1 \times \text { Pure Energy }
$$

$1 \times$ Aquecedor Thermans Vertical $300 \mathrm{~L}$

$$
1 \times 2018 \text { Nissan Leaf }
$$

$26 \times$ CS CS5P-250M

$1 \times$ Tesla Powerwall

5 x Kit Gerado de Turbina Eólica 1.5kW
Vida útil



$\begin{array}{rrl}25 & 13.771 & 20.656,50 \\ 10 & 41.250 & 61.875,00 \\ 5 & 4.234 & 6.351,00 \\ 5 & 1400 & 2.100,00 \\ 10 & 5.620 & 8.430,00 \\ 5 & 199.000 & 199.000,00 \\ 25 & 25.575 & 38.362,07 \\ 10 & 21.780 & 32.670,00 \\ 5 & 10.585 & 15.877,50\end{array}$

Para EV e veículo a combustão interna, o preço de combustível considerado é $\mathrm{R} \$ 4,50$ por litro, com aumento anual de $3 \%$.

\subsubsection{Dados sobre a residência}

O limite pico de aquisição de potência de entrada da residência é $75 \mathrm{~kW}$, que é a capacidade residencial no Brasil. A altura da casa, com dois andares, é $6.0 \mathrm{~m}$, com área construída igual a $250 \mathrm{~m} 2$.

No presente estudo de caso, a casa não possui EV, WH, SC, WT, Bateria e PV. Este trabalho utiliza as especificações técnicas para cada SCH conforme Dutra et al. (2018).

A temperatura de entrada da água foi determinada com os dados de Silva et al. (2011 - Gráfico 4). Projetamos os intervalos ausentes para que o último valor projetado seja igual ao primeiro valor coletado. Para a demanda de água na residência, usamos os dados disponíveis em DeOreo et al. (2016), agregando o consumo diário em intervalos de tempo igual a 10 minutos. 
O número de vezes que os moradores saem da residência com veículos é definido seguindo uma distribuição uniforme $U(1,4)$ e os tempos da viagem gerados aleatoriamente seguindo uma distribuição normal $N(0.5,2)$ horas, exceto viagens previstas para trabalho, as quais tem distribuição normal $\mathrm{N}(8,2)$.

\section{Resultados}

Para cada um dos 511 projetos, existe um fluxo de caixa. Se considerarmos manutenção, existem inúmeros fluxos de caixa para cada projeto. Logo, não é condizente com a publicação de um artigo exibir todos os fluxos de caixa deste trabalho, mas utilizando os dados da Tabela 1, pode-se construir todos os 511 fluxos de caixa. No entanto, apresentamos dois exemplos para fins de compreensão dos resultados. Suponha um SHC "a" com vida útil de 12 anos e valor de aquisição igual a $\mathrm{R} \$$ " $\mathrm{x}$ " e um outro SHC "b" com vida útil de 10 anos e valor de aquisição de R\$̦ " $y$ ". Cada projeto terá sua própria economia em cada ano i, o que será representado por $\mathrm{Si}: i \in\{1,2 . .25\}$. Com isso, os fluxos de caixas para 3 projetos são exibidos no Quadro 2.

\section{Quadro 2}

Exemplo de fluxos de caixa

\begin{tabular}{|c|c|c|c|c|c|}
\hline \multicolumn{2}{|c|}{ Projeto com "a" } & \multicolumn{2}{|c|}{ Projeto com "b" } & \multicolumn{2}{|c|}{ Projeto com "a" e "b" } \\
\hline Ano & Fluxo & Ano & Fluxo & Ano & Fluxo \\
\hline 1 & S1-x & 1 & S1-y & 1 & S1-y-x \\
\hline 2 & S2 & 2 & S2 & 2 & S2 \\
\hline 3 & S3 & 3 & S3 & 3 & S3 \\
\hline 4 & S4 & 4 & S4 & 4 & S4 \\
\hline 5 & S5 & 5 & S5 & 5 & S5 \\
\hline 6 & S6 & 6 & S6 & 6 & S6 \\
\hline 7 & S7 & 7 & S7 & 7 & S7 \\
\hline 8 & S8 & 8 & S8 & 8 & s8 \\
\hline 9 & S9 & 9 & S9 & 9 & S9 \\
\hline 10 & S10 & 10 & S10 & 10 & S10 \\
\hline 11 & S11 & 11 & S11-y & 11 & S11-y \\
\hline 12 & S12 & 12 & S12 & 12 & S12 \\
\hline 13 & S13-x & 13 & S13 & 13 & S13-x \\
\hline 14 & S14 & 14 & S14 & 14 & S14 \\
\hline 15 & S15 & 15 & S15 & 15 & S15 \\
\hline 16 & S16 & 16 & S16 & 16 & S16 \\
\hline 17 & S17 & 17 & S17 & 17 & S17 \\
\hline 18 & S18 & 18 & S18 & 18 & S18 \\
\hline 19 & S19 & 19 & S19 & 19 & S19 \\
\hline 20 & $\mathrm{~S} 20$ & 20 & $\mathrm{~S} 20$ & 20 & $\mathrm{~S} 20$ \\
\hline 21 & S21 & 21 & $\mathrm{~S} 21-\mathrm{y}$ & 21 & S21 -y \\
\hline 22 & S22 & 22 & $\mathrm{~S} 22$ & 22 & S22 \\
\hline 23 & S23 & 23 & $\mathrm{~S} 23$ & 23 & $\mathrm{~S} 23$ \\
\hline 24 & S24-x & 24 & S24 & 24 & S24-x \\
\hline 25 & $\mathrm{~S} 25$ & 25 & S25 & 25 & $\mathrm{~S} 25$ \\
\hline
\end{tabular}

Fonte: Autoria própria. 
O Quadro 2 mostra 3 projetos possíveis para um investidor. No projeto com a SHC "a", um componente "a" deve ser comprado no início do projeto, ou seja, no ano 1, com custo de $\mathrm{R} \$ \mathrm{x}$. Após a sua vida útil de 12 findar, um novo componente deve ser comprado no ano 13, incorrendo novamente em um custo de R\$ x. Por fim, após a vida útil deste segundo componente terminar, um novo componente deve ser comprado no ano 24 , incorrendo novamente em um custo de $\mathrm{R} \$ \mathrm{x}$. De forma similar ocorre com o projeto com SHC "b". Por fim, o projeto com ambos SHC, tem custos anualizados conforme a vida útil de cada componente.

Analisa-se a partir deste ponto, o caso em estudo com os dados reais elencados na subseção 3.2.

Embora os sistemas compostos apenas por PVs tenham um payback inferior à duração do projeto e um retorno sobre o investimento positivo, o VPL mostra que eles não valem a pena para esta casa. Assim, tanto o payback quanto o cálculo do retorno sobre o investimento deve ser evitado. Por um outro lado, sistemas compostos com apenas turbinas eólicas têm VPL positivo proporcional à capacidade instalada.

Para o caso em consideração, as baterias são muito caras e devem ser evitadas. Todo projeto que contém bateria tem um VPL inferior ao respectivo conjunto sem bateria, exceto projetos com PVs. A combinação de PVs com baterias tem um efeito sinérgico na melhoria do VPL em relação aos sistemas no qual PVs ou, exclusivamente, baterias são usados. No entanto, o VPL é ainda negativo. O preço de uma bateria Tesla deve diminuir para cerca de R\$5500 para que o projeto sem geração renovável tenha um VPL positivo. Se consideramos a vida útil de uma bateria igual a 25 anos, um pack de bateria deve custar cerca de R\$7500 para se obter um VPL positivo. Os sistemas compostos por uma bateria e PVs ou por uma bateria e SC têm VPL negativo. No sistema WT 7kW e bateria $13 \mathrm{kWh}$, o preço da bateria deve estar em torno de R\$5500 para corresponder ao VPL do sistema com WT 7kW sozinho.

O EV é extremamente caro no país. Para a residência em estudo, seu preço deve ser no máximo de $\mathrm{R} \$ 35000$ para valer o custo. Se o tomador de decisão vai comprar um carro de preço $\mathrm{R} \$ x$, o preço de um EV deve ser no máximo $x+35000$ para ter uma situação de empate. Se considerarmos uma vida útil de 10 anos para EV, o preço deve ser no máximo de R\$ 52000 para ter um VPL positivo. Vamos considerar dois cenários com custos de manutenção. No primeiro, no sexto ano após a vida útil do EV, R\$ 1000 são alocados para manutenção e esse custo é aumentado em R\$ 300 para cada ano subsequente. Uma ideia semelhante é aplicada no segundo cenário até o décimo quarto ano. Neste o EV é vendido por $\mathrm{R} \$ 80000$ e um novo EV é comprado. Então, de décimo quinto ao décimo nono ano, o custo de manutenção é nulo, mas no vigésimo ano, uma quantia de $\mathrm{R} \$ 1000$ foi alocada para manutenção e esse custo é aumentado em R\$ 300 para cada ano subsequente. O VPL é de -139 e -156 mil reais para o cenário um e dois, respectivamente. Portanto, o EV não é benéfico em termos de dinheiro. 
Em complemento ao chuveiro elétrico, o sistema SC é uma opção melhor para aquecimento de água. O sistema SC tenha VPL maior que o sistema composto por WH e SC ou o sistema composto por somente WH. Aliás, este último sistema tem VPL negativo.

Para esta residência, o conjunto $\{W T 3 \mathrm{~kW}, \mathrm{WT} 7.5 \mathrm{~kW}\}$ fornece o melhor VPL de R\$130.696. Logo, instalar somente a turbina eólica com 10kW é a melhor opção financeira. Note que este resultado é diferente comparada uma residência localizada a $20 \mathrm{~km}$ da residência estudada neste artigo, conforme reportado em Dutra, (2020), sendo importante o estudo individual, caso a caso. Além disso, apesar de Fortaleza ter bons níveis de irradiância solar, esta residência não deveria instalar placa solares.

\section{Conclusão}

Casas inteligentes tem uma tendência forte de crescimento para o futuro em muitos países. No entanto, essa tendência é menos acentuada no Brasil. Este estudo considera que a falta de informações sobre o investimento em casas inteligentes pode ser um fator inibidor na transição de casas atuais para casas inteligentes no Brasil. Inexiste estudos para guiar um investidor cearense na adoção de uma casa inteligente. De forma objetiva, este trabalho contribui com a literatura respondendo a seguinte pergunta: "Financeiramente, é viável a adoção de uma casa inteligente para qualquer residência no Ceará". Visando a contribuir socialmente nessa transição, este trabalho apresenta um estudo de caso sobre investimentos em 511 projetos de casa inteligente para uma residência localizada em Fortaleza, Ceará. Programação matemática para otimização do valor presente líquido é utilizada com modelos detalhados para as componentes de uma casa inteligente. Resultados indicam o melhor projeto para a residência estudada, ou seja, aquele com maior valor presente líquido. Apesar do nordeste ser uma região com alto nível de radiação solar, para o caso em estudo, o proprietário não tem um investimento com retorno positivo se instalar painéis fotovoltaicos. Coletores solares são uma boa opção para aquecimento de água, mas não compõe o projeto com melhor valor presente líquido. Turbinas eólicas são extremamente vantajosas, sendo o melhor a instalação de uma turbina eólica de $10 \mathrm{~kW}$ o melhor projeto para maximizar o valor presente líquido. Veículos elétricos são extremamente caros para se ter viabilidade econômica. Como trabalho futuro, deseja-se utilizar dados coletados via sensores e termômetros para fazer uma comparação qualitativa e quantitativa sobre a variação do investimento em relação a dados estimados. Em relação as limitações do estudo, salienta-se que o presente estudo pode ser melhorado se houver investimento na aquisição de sensores, termômetros e outros aparelhos de coleta de dados para utilização de dados que sejam próprios da residência em estudo. 


\section{Referências}

Anvari, S., Desideri, U., \& Taghavifar, H. (2020). Design of a combined power, heating and cooling system at sized and undersized configurations for a reference building: Technoeconomic and topological considerations in Iran and Italy. Applied Energy, 258, 114105.

https://doi.org/10.1016/j.apenergy.2019.114105

Akter, M. N., Mahmud, M. A., \& Oo, A. M. (2017). Comprehensive economic evaluations of a residential building with solar photovoltaic and battery energy storage systems: An Australian case study. Energy and Buildings, 138, 332-346.

http://dx.doi.org/10.1016/j.enbuild.2016.12.065

Handbook, A. F., \& Fundamentals, H. V. A. C. (2013). Sl edition. American Society of Heating, Refrigerating, and Air-Conditioning Engineers-Atlanta-2013.

https://www.ashrae.org/technical-resources/ashrae-handbook

Bai, B., Xiong, S., Song, B., \& Xiaoming, M. (2019). Economic analysis of distributed solar photovoltaics with reused electric vehicle batteries as energy storage systems in China. Renewable and Sustainable Energy Reviews, 109, 213-229. https://doi.org/10.1016/j.rser.2019.03.048

Beck, T., Kondziella, H., Huard, G., \& Bruckner, T. (2017). Optimal operation, configuration and sizing of generation and storage technologies for residential heat pump systems in the spotlight of selfconsumption of photovoltaic electricity. Applied Energy, 188, 604-619.

http://dx.doi.org/10.1016/j.apenergy.2016.12.041

Chatzisideris, M. D., Ohms, P. K., Espinosa, N., Krebs, F. C., \& Laurent, A. (2019). Economic and environmental performances of organic photovoltaics with battery storage for residential selfconsumption. Applied Energy, 256, 113977. https://doi.org/10.1016/j.apenergy.2019.113977

Coffman, M., Bernstein, P., \& Wee, S. (2017). Integrating electric vehicles and residential solar PV. Transport Policy, 53, 30-38. https://doi.org/10.1016/j.tranpol.2016.08.008

Coria, G., Penizzotto, F., \& Pringles, R. (2019). Economic analysis of photovoltaic projects: The Argentinian renewable generation policy for residential sectors. Renewable Energy, 133, 11671177. https://doi.org/10.1016/j.renene.2018.08.098

Dranka, G. G., \& Ferreira, P. (2020). Towards a smart grid power system in Brazil: Challenges and opportunities. Energy Policy, 136, 111033. https://doi.org/10.1016/j.enpol.2019.111033

DeOreo, W. B., Mayer, P. W., Dziegielewski, B., \& Kiefer, J. (2016). Residential end uses of water, version 2. Water Research Foundation. https://www.waterrf.org/research/projects/residential-end-uses-water-version-2

de Souza Dutra, M. D., Anjos, M. F., \& Le Digabel, S. (2019). A realistic energy optimization model for smart-home appliances. International Journal of Energy Research, 43(8), 3237-3262. https://doi.org/10.1002/er.4454

de Souza Dutra, M. D., Anjos, M. F., \& Le Digabel, S. (2019). A general framework for customized transition to smart homes. Energy, 189, 116138.

http://dx.doi.org/10.1016/j.energy.2019.116138 
de Souza Dutra, M. D., da Conceição Júnior, G., de Paula Ferreira, W., \& Chaves, M. R. C. (2020). A customized transition towards smart homes: A fast framework for economic analyses. Applied Energy, 262, 114549. https://doi.org/10.1016/j.apenergy.2020.114549

Espinoza, R., Muñoz-Cerón, E., Aguilera, J., \& de la Casa, J. (2019). Feasibility evaluation of residential photovoltaic self-consumption projects in Peru. Renewable energy, 136, 414-427. http://dx.doi.org/10.1016/j.renene.2019.01.003

Gur, K., Chatzikyriakou, D., Baschet, C., \& Salomon, M. (2018). The reuse of electrified vehicle batteries as a means of integrating renewable energy into the European electricity grid: A policy and market analysis. Energy Policy, 113, 535-545. https://doi.org/10.1016/j.enpol.2017.11.002

Kichou, S., Skandalos, N., \& Wolf, P. (2019). Energy performance enhancement of a research centre based on solar potential analysis and energy management. Energy, 183, 1195-1210. https://doi.org/10.1016/j.energy.2019.07.036

Leite, A. P., Falcão, D. M., \& Borges, C. L. (2006). Modelagem de usinas eólicas para estudos de confiabilidade. Sba: Controle \& Automação Sociedade Brasileira de Automatica, 17(2), 177188. https://www.scielo.br/j/ca/a/m4yB8F9kVy74sb7qwPg39Yz/?lang=pt

Mazzeo, D. (2019). Nocturnal electric vehicle charging interacting with a residential photovoltaicbattery system: a 3E (energy, economic and environmental) analysis. Energy, 168, 310-331. https://doi.org/10.1016/j.energy.2018.11.057

Menezes, H. L. D. S. (2014). Avaliação da aplicação da modalidade tarifária horária branca: Estudo de caso para consumidores residenciais. https://bdm.unb.br/bitstream/10483/9743/1/2014_HenriqueLeaodeSaMenezes.pdf

O'Shaughnessy, E., Cutler, D., Ardani, K., \& Margolis, R. (2018). Solar plus: A review of the end-user economics of solar PV integration with storage and load control in residential buildings. Applied energy, 228, 2165-2175. https://doi.org/10.1016/j.apenergy.2018.07.048

Sanguinetti, A., Karlin, B., \& Ford, R. (2018). Understanding the path to smart home adoption: Segmenting and describing consumers across the innovation-decision process. Energy research \& social science, 46, 274-283. https://doi.org/10.1016/j.erss.2018.08.002

Say, K., John, M., Dargaville, R., \& Wills, R. T. (2018). The coming disruption: The movement towards the customer renewable energy transition. Energy Policy, 123, 737-748.

https://doi.org/10.1016/j.enpol.2018.09.026

Schopfer, S., Tiefenbeck, V., \& Staake, T. (2018). Economic assessment of photovoltaic battery systems based on household load profiles. Applied energy, 223, 229-248. https://doi.org/10.1016/j.apenergy.2018.03.185

da Silva, A. J., Nascimento, C. R. C., da Silva, L. F., \& Lucas, T. D. P. B. (2011). Análise topoclimática em unidade de conservação urbana a partir da temperatura e umidade relativa do ar. eScientia, 4(1), 21-30. https://www.ufmg.br/estacaoecologica/portfolio-item/analisetopoclimatica-em-unidade-de-conservacao-urbana-a-partir-da-temperatura-e-umidaderelativa-do-ar/

Uddin, K., Gough, R., Radcliffe, J., Marco, J., \& Jennings, P. (2017). Techno-economic analysis of the viability of residential photovoltaic systems using lithium-ion batteries for energy storage in 
the United Kingdom. Applied Energy, 206, 12-21.

https://doi.org/10.1016/j.apenergy.2017.08.170

Van Der Stelt, S., AISkaif, T., \& van Sark, W. (2018). Techno-economic analysis of household and community energy storage for residential prosumers with smart appliances. Applied Energy, 209, 266-276. https://doi.org/10.1016/j.apenergy.2017.10.096

Xie, Y., Gilmour, M. S., Yuan, Y., Jin, H., \& Wu, H. (2017). A review on house design with energy saving system in the UK. Renewable and Sustainable Energy Reviews, 71, 29-52. https://doi.org/10.1016/j.rser.2017.01.004

$\mathrm{Yu}, \mathrm{H}$. J. J. (2018). A prospective economic assessment of residential PV self-consumption with batteries and its systemic effects: The French case in 2030. Energy Policy, 113, 673-687. https://doi.org/10.1016/j.enpol.2017.11.005. 